\title{
Psidium Guajava Leave Extract as Reducing Agent for Synthesis of Zinc Oxide Nanoparticles and its Application to Impart Multifunctional Properties for Cellulosic Fabrics
}

\author{
Menna Zayed ${ }^{1(D)}$, Hanan Othman ${ }^{1}$, Heba Ghazal ${ }^{1}$, Ahmed G. Hassabo ${ }^{2, *}$ (D) \\ 1 Textile Printing, Dyeing and Finishing Department, Faculty of Applied Arts, Benha University, Benha, Egypt \\ 2 National Research Centre (Scopus affiliation ID 60014618), Textile Industries Research Division, Pretreatment, and \\ Finishing of Cellulose-based Textiles Department, 33 El-Behouth St. (former El-Tahrir str.), Dokki, P.O. 12622, Giza, \\ Egypt \\ * Correspondence: aga.hassabo@hotmail.com;
}

Scopus Author ID: 55909104700

Received: 7.01.2021; Revised: 3.02.2021; Accepted: 5.02.2021; Published: 13.02.2021

\begin{abstract}
Nowadays, cotton fabric treatment with nanoparticles has been increasingly high because of its unique properties. In this study, using the bioactive compounds in Psidium guava leave extracts, zinc precursors were reduced to obtain $\mathrm{ZnO}$ nanoparticles using two extracts, namely, water extract and ethanol extract. A comparative evaluation was carried out to analyze and develop a wider understanding of the effect of processing parameters on the $\mathrm{ZnO}$ nanoparticles. The $\mathrm{ZnO}$ nanoparticles have been characterized using a particle size analyzer, Transmission Electronic Microscopy (TEM), X-ray diffraction, and Thermal Gravimetrical Analysis (TGA) to determine their structure. The cotton fabric was treated with $\mathrm{ZnO}$ nanoparticles in the presence and absence of different natural biopolymers, namely; alginate, chitosan, and carboxymethyl cellulose (CMC). The treated cotton samples were characterized by atomic absorption and scanning electron microscopy (SEM), UPF value, antimicrobial activity, and self-cleaning properties. It was found that the cotton fabric treated with $\mathrm{ZnO}$-chitosan nanocomposites gives the higher UPF values and antimicrobial activity against Staphylococcus aureus, Escherichia coli, and Candida albicans of all other treated fabrics.
\end{abstract}

Keywords: cotton fabric; Psidium guajava leave extract; nanotechnology; zinc oxide nanoparticles; antibacterial; self-cleaning; ultraviolet protection.

(C) 2021 by the authors. This article is an open-access article distributed under the terms and conditions of the Creative Commons Attribution (CC BY) license (https://creativecommons.org/licenses/by/4.0/).

\section{Introduction}

In modern materials science, nanotechnology is one of the most active research domains. Nanoparticles are of distinct properties compared with bulk types of the same substance based on their particular characteristics such as size, distribution, and morphology. A nanoparticle (nano-powder, nanocluster, or nanocrystal) is a microscopic particle of less than $100 \mathrm{~nm}$ in at least one dimension [1].

Much work has been devoted in recent years to adding nanoparticles of metal oxide to textile materials for the production of multifunctional fabrics with new and improved properties or removing the heavy metal from wastewater [2-14]. The cotton fabric was commonly used in garments and other products of everyday use because of its softness and comfort, but it also has some low performance, such as proneness to bacteria, vulnerability 
to UV, hydrophilic, etc. with the enhancement of the health concept, the interests of multifunctional cotton were followed by more and more scientists [15-26].

$\mathrm{ZnO}$ nanoparticles are among the metal oxides used to treat materials because of their uniqueness of characteristics such as chemical stability, non-toxicity, antibacterial and UV protection, high photocatalytic activity, and high clarity of the visible wavelength spectrum [27-29].

The $\mathrm{ZnO}$ nanoparticles can be synthesized through various routes, such as chemical reduction, microwave, and green route procedures. [30] But there are several problems associated with chemical methods. Therefore, much attention was given to the green route method of nanoparticle synthesis as an alternative method for synthesizing nanoparticles due to its cost-effectiveness and reducing the dangerous chemical compound's use [31]. The biosynthesis of ZnO NPs through the green route was a promising domain in nanotechnology due to their uses of active Phyto-compounds, which employ as a reducing and capping agent [32].

Psidium guajava leaves can be used as a biocatalyst / chelating agent to synthesize $\mathrm{ZnO}$ NPs from zinc acetate precursors because they have high polyphenols, carotenoids, terpenoids, flavonoids, and triterpenes in the crude water and ethanol extracts of the leaves [33]. These biomolecules have functional groups and can coordinate with $\mathrm{Zn}$ (II) ions, thereby facilitating and stabilizing the formation of $\mathrm{ZnO}$ NPs [34].

Researchers recently tried to functionalize cotton fabrics with bio-Nanocomposites, i.e., natural polymer matrix components combined with nano-scale organic/inorganic metal particles because of their simple accessibility and low toxicity. [35-37] For example, the metal oxide Nanoparticles-chitosan Nanocomposite, as mentioned in earlier research, is used in antibacterial cotton fabric working and also in hydrophobic surfaces to minimize sweat absorption [28].

The goal of this study was to investigate the Characterization of the ZnO NPs that synthesized using psidium guava leaves extracts Through changing the processing parameters and provide an excellent functional property to cotton fabric by treatment the fabric using $\mathrm{ZnO}$ NPs and its composites

\section{Materials and Methods}

\subsection{Materials.}

Bleached scoured cotton fabric $\left(220 \mathrm{~g} / \mathrm{m}^{2}\right)$ supplied by Ghazel El-Mahala for Textile Industry Co., Egypt, was used during this research. Psidium guajava leaves (Psidium guajava L.) were purchased from an agricultural farm in Egypt in Egypt. Ethanol (95\%), sodium carbonate $\left(\mathrm{Na}_{2} \mathrm{CO}_{3}\right)$, citric acid, sodium hypophosphite (SHP), and sodium carbonate were provided from Fluka. Zinc acetate was purchased from El Nasr pharmaceutical chemicals Co. Alginate purchased from Fluka BioChemica GmbH Co., carboxymethyl cellulose purchased from Carl Roth GmbH Co. chitosan low molecular weight (100000-300000) was purchased from ACROS Co. All the chemicals and reagents were used as received without purification. 


\subsection{Methods.}

\subsubsection{Preparation of Psidium guajava leaves (Psidium guajava L.) extract.}

The freshly Psidium guajava leaves were collected, washed, and cleaned with water to remove the dust. The dried leaves were cut into small pieces. The extraction of Psidium guajava L was done using two solvents, namely water and ethanol. For aqueous extraction, $100 \mathrm{~g}$ from the leave pieces was placed in $1 \mathrm{~L}$ boiled water for $60 \mathrm{~min}$. The extract was subjected to vacuum filtration with the Whatman Filter Paper no. 1. Extraction was then stored at a temperature of $4^{\circ} \mathrm{C}$ and used without any further purification. For ethanolic extraction, $200 \mathrm{~g}$ from the leave pieces were placed on the Soxhlet device in $1 \mathrm{~L}$ ethanol. The temperature was adjusted to $70^{\circ} \mathrm{C}$ and kept for four hours. The extract was subjected to vacuum filtration with the Whatman Filter Paper no. 1. The extraction was then stored at a temperature of $4^{\circ} \mathrm{C}$ and used without any further purification.

\subsubsection{Synthesis of zinc oxide nanoparticles (ZnO NPs) using Psidium guajava L. extract.}

Zinc oxide nanoparticles ( $\mathrm{ZnO}$ NPs) have been synthesized using the modified method from the reported one by Rajendra et al. [38] from zinc acetate as precursors and reduced in the presence of Psidium guajava $\mathrm{L}$ extract in water or ethanol as a capping agent by use of sodium carbonate to adjust the $\mathrm{pH}$ medium to $(8,10$, and 12$)$.

In this modified procedure, $70 \mathrm{ml}$ of the Psidium guajava L extract in water or ethanol (as a capping agent) was placed in a beaker. The $\mathrm{pH}$ medium was adjusted to $(8,10$, or 12$)$ using sodium carbonate $(10 \%)$. After that, the solution temperature was rais ed to $70^{\circ} \mathrm{C}$, that $1 \mathrm{~N}$ zinc acetate in $30 \mathrm{ml}$ distilled water was added to the solution of Psidium guajava $\mathrm{L}$ extract drop by drop under stirring for 30 minutes. Then the solution was kept at this temperature for 90 min under stirring. The produced powder was filtered and dried at $90^{\circ} \mathrm{C}$ for $24 \mathrm{~h}$. The produced powder was combinations of $\mathrm{Zn}(\mathrm{OH})_{2}$ and $\mathrm{Zn}\left(\mathrm{CO}_{3}\right)_{2}$ or combinations between them as $\mathrm{Zn}_{5}(\mathrm{OH})_{6}\left(\mathrm{CO}_{3}\right)_{2}$ [6]. So, the calcination step is important to forming $\mathrm{ZnO}$ NPs at it was done at $400^{\circ} \mathrm{C}$ for $4 \mathrm{hr}$. The calcinated $\mathrm{ZnO}$ NPs were used for further use.

\subsubsection{Treatment of cotton fabric with Psidium guajava L. extract.}

Cotton fabrics were pre-treated with citric acid (10 g/l) and sodium hypophosphite (5 $\mathrm{g} / \mathrm{l})$ using the pad-dry method through immersing in the treated bath for $5 \mathrm{~min}$ and squeezed with $100 \%$ wet pickup, then dried at $100^{\circ} \mathrm{C}$ for $3 \mathrm{~min}$.

$\mathrm{ZnO}$ NPs emulsion for fabric treatments was prepared in distilled water to obtain 10 $\%$ in the presence of $10 \mathrm{~g} / \mathrm{l}$ different polymeric materials (alginate, carboxymethyl cellulose, and chitosan) according to the following procedure: $1 \mathrm{~g}$ polymeric material was dissolved in $100 \mathrm{ml}$ distilled water under stirring. At $80^{\circ} \mathrm{C}, 1 \mathrm{~g}$ calcinated $\mathrm{ZnO}$ NPs was added under vigorous stirring, the stirring was continued for $30 \mathrm{~min}$ for good distribution of the nanoparticle inside the polymer network. After that, the solution was homogenized using a homogenizer for $3 \mathrm{~min}$ at $20000 \mathrm{rpm}$ to ensure a completely homogenous distribution.

Pre-treated cotton fabric was immersed in the final produced emulsion for $10 \mathrm{~min}$, then squeezed with $100 \%$ wet pickup and dried at $100^{\circ} \mathrm{C}$ for $5 \mathrm{~min}$ and cured at $140^{\circ} \mathrm{C}$ for 3 min. The treated fabric was used for further investigation. 


\subsection{Analysis and Measurements.}

\subsubsection{Transmission Electronic Microscopy (TEM).}

Transmission Electron Microscopy (TEM) images for synthesized ZnO NPs were investigated with a JEOL JEM-1200 EX transmission electron microscope operating at 120 $\mathrm{kV}$. For TEM characterization, the ultrasound bath was used to diffuse a small volume of $\mathrm{ZnO}$ NPs into distilled water. One drop of the dispersion was placed on a copper grid.

\subsubsection{Scanning Electron Microscopy (SEM).}

Scan electron microscopy was used to analyze the surface and internal structure of the treated cotton fabrics with ZnO NPs using SEM; JEOL, JSM-6360LA, Japan. For the indication of contents or distribution of metals on the fabric surface, SEM is connected with Energy Dispersive Spectroscopy (EDX).

\subsubsection{Particle Size Analyzer.}

The particle size measurements of the synthesized $\mathrm{ZnO}$ NPs were investigated by the laser particle size analyzer MasterSizer/2000; MALVERN Instruments, UK, according to standard test methods ASTM E11:61 [39], ISO 3310-1:2016 [40], and ISO 565: 1990 [41].

\subsubsection{Atomic absorption.}

A multi-element flame atomic absorption spectrometer, SpectrAA Varian Type220, was employed to determine the treated fabric $\mathrm{Zn}$ content. A hollow cathode multi-element lamp was used for zinc determination at $213.9 \mathrm{~nm}$ wavelength with bandwidths of $1 \mathrm{~nm}$. The flame composition was the air with $13.5 \mathrm{~L} / \mathrm{min}$.

\subsubsection{X-ray diffractometry.}

The crystallinity of the synthesized ZnO NPs after calcination was studied using Xray diffractometry. The macro-structural characteristics of materials like the crystallinity, the crystal size, and the crystals' orientation are important for X-ray diffractometry.

\subsubsection{Thermogravimetrically Analysis (TGA).}

TGA thermographs of treated textiles were analyzed for a temperature range from room temperature to $600^{\circ} \mathrm{C}$ with a heating rate of $10^{\circ} \mathrm{C} / \mathrm{min}$ at in air atmosphere using NETZSCH STA 2500 Regulus (German). The weight of the fabric sample was 4-9 $\mathrm{mg}$

\subsubsection{Contact angle and wettability time.}

The contact angle was reported at atmospheric conditions $\left(25^{\circ} \mathrm{C}\right)$ on Dataphysics GmbH (OCA-15EC) according to ASTM D7334-08 standard form [42]. Wettability time has been investigated to drop water on the surface of treated fabric until completely penetrated through the fabric surface [43]. 


\subsubsection{Self-cleaning action.}

The self-cleaning action of the treated cotton fabrics was demonstrated following the suitable described method by Ibrahim et al. [44], which can be described as follow: The untreated and treated fabrics with $\mathrm{ZnO}$ NPs with/without biopolymer were immersed in methylene blue solution $(0.02 \%)$ for $30 \mathrm{~min}$ and dried overnight in air. After that, the samples were exposed to UV light for 24, 48, and $72 \mathrm{~h}$. Colour strength values (K/S) of the dyed fabrics were measured using a Hunter lab's Ultra Scan PRO spectrophotometer (USA).

\subsubsection{The UV-Protection Factor (UPF).}

The UV-protection factor (UPF) for untreated and treated samples of cotton fabric was determined by the Australian/New Zealand standard (AS/NZS 4366-1996) [45]. The ultraviolet transmission through the fabric was determined by a Cary Varian $300 \mathrm{UV}-\mathrm{Vis}$ spectrophotometer $[5,8,9,19,46,47]$.

\subsubsection{Color strength $(\mathrm{K} / \mathrm{S})$.}

The color strength (K/S) and whiteness degrees of the untreated, treated, and dyed fabrics were evaluated using Hunter Lab Ultra Scan PRO (USA, 2007). The relative color strength $(K / S)$ of the cotton fabrics was measured and assessed by applying the KubelkaMunk equation as following [48-57]:

$$
K / S=\frac{(1-R)^{2}}{2 R}-\frac{\left(1-R_{o}\right)^{2}}{2 R_{o}}
$$

where $K$ is the absorption coefficient, $S$ is the scattering coefficient, $R_{o}$ is the reflectance of the uncolored (white) sample, and $R$ is the reflectance of the colored sample.

2.3.11. Mechanical and physical properties of the treated fabric.

Tensile strength and elongation at break are conducted on a tensile strength apparatus type FMCW 500 (Veb Thuringer Industrie Werk Rauenstein $11 / 2612$ Germany) at $25^{\circ} \mathrm{C}$ and $65 \%$ relative humidity according to the ASTM Test Method D1682-59T. [58] The dry crease recovery angle (CRA) was measured according to AATCC Test Method 66 - 2014. [59] Fabric roughness was measured using Surface Roughness measuring instrument SE 1700 a using ASTM Test Method D 7127 - 13 [60]. Stiffness was performed using the cantilever apparatus according to ASTM test method D 1388-14e1 [61].

\subsubsection{Antibacterial activity.}

The antibacterial activity was quantitatively examined using the AATCC 100-2012 (bacterial reduction method) [24,62,63] and quantitively tested using disc diffusion to analyze the antimicrobial activity of treated fabrics according to the AATCC Test Method (147-2016) $[8,10,64,65]$. Both examined methods were done against Staphylococcus aureus (ATCC 29213) as a gram-positive bacteria and Escherichia coli (ATCC 25922) and Candida albicans (ATCC 10231) as a fungus.

\subsubsection{Durability.}

The durability of treatment and imparted properties to the fabric were evaluated by washing the treated cotton fabric with $2 \mathrm{~g} / \mathrm{l} \mathrm{Hostapal} \mathrm{(non-ionic} \mathrm{detergent)} \mathrm{for} 10 \mathrm{~min}$ at $40^{\circ} \mathrm{C}$ 
and drying at $100^{\circ} \mathrm{C}$ for $3 \mathrm{~min}$ (for each washing cycle). After that, the investigated properties were re-examined again after selected washing cycles.

\section{Results and Discussion}

In the presence of Psidium guajava L extract as a capping agent, the preparation of nanoparticles of zinc oxide was studied through hydrolyzed with sodium carbonate at various pHs. Also, the produced ZnO NPs were characterized using a TGA, XRD, and TEM.

\subsection{Characterization of synthesized $\mathrm{ZnO}$ NPs.}

Guava leaves consist of several biological molecules that offer desirable health benefits, such as phenols, flavonoids, and essential oils. Guava leaf compounds are bio-active and solvent-soluble. The difference in solvent polarity is influencing chemical components' solubility and extraction production. Therefore, choosing the right solvent is one of the main steps to enhance the extraction process.

Guava leaves were eventually extracted in two solvents, namely water and ethanol. Both extracts in water and ethanol have been used to synthesize $\mathrm{ZnO}$ NPs at different $\mathrm{pH}(8$, 10, and 12).

The particle size of synthesized $\mathrm{ZnO}$ nanoparticles using Psidium guajava L. extract was observed and illustrated in Figure 1. The particle size of ZnO NPs synthesized with Psidium guajava $\mathrm{L}$ in various $\mathrm{pH}$ media $(8,10$, and 12) is shown in Figure 1. Extract from various $\mathrm{pH}$ media in water and alcohol $(8,10$, and 12$)$. It is apparent that, by growing the $\mathrm{pH}$ medium, the particles in synthesized ZnO NPs decrease. The deposited effect of Psidium components on the $\mathrm{ZnO}$ NPs surface could be attributed to this decreasing.

It is further noted that the particle size of the synthesized $\mathrm{ZnO}$ NPs with Psidium guajava L. extract in water is higher than those in alcohol in different $\mathrm{pH}(8,10$, and 10) medium. It is clear that the particle size of synthesized ZnO NPs using both Psidium guajava L. extract provides a three size at both $\mathrm{pH} 8$ and 10; these sizes are around (5-7, 12-18, and 110-170 nm) and (< 1, 5-7, and 80-90 nm) for guajava L. extract in water and ethanol respectively. The main particle size was in the second peak (12-18 and 5-7) for guajava L. extract in water and ethanol, respectively. At $\mathrm{pH} 12$, the particle size of synthesized ZnO NPs using both Psidium guajava L. extract provides two sizes. These sizes are around ( 3 and 12 $\mathrm{nm})$ and $(8$ and $9 \mathrm{~nm})$ for guajava L. extract in ethanol and water, respectively, with the main particle size in the second peak for both extracts.

There can be no doubt that at $\mathrm{pH} 8 \mathrm{ZnO}$ NPs are very close to synthesis in both extracts, while the $\mathrm{pH}$ medium increases to 10 causes $\mathrm{ZnO}$ NPs to start to develop. Therefore, the synthesized $\mathrm{ZnO}$ NPs have been increased as the $\mathrm{pH}$ medium in both extracts increases. Furthermore, in the ethanolic extract, the formation of $\mathrm{ZnO}$ NPs is smaller than in water extract. Moreover, for shaping $\mathrm{ZnO}$ NPs in both extracts, $\mathrm{pH} 12$ proved to be an excellent medium.

The coordinated $\mathrm{ZnO}$ NPs have been studied to decompose reduced zinc oxide with Psidium guajava L by thermo-gravimetrical analyses (TGA). Figure 2 indicates water loss accompanied by capping agents' decomposition at approximately $290,310^{\circ} \mathrm{C}$ in the first stage of the thermal decomposition profile, respectively, in water and ethanol extract. However, the decomposition step ends around $310-320^{\circ} \mathrm{C}$ except for $\mathrm{ZnO}$ NPs from ethanol extract at 
pH 12; thus, the decomposition step end at $385^{\circ} \mathrm{C}$. This step also enhances the weight loss percent from 20 to $58 \%$ and from 35 to $55 \%$ for water and ethanol extract, respectively.

Last phase stopping at $600^{\circ} \mathrm{C}$ offers an improvement of $15 \%$ to $30 \%$ and 25 to $40 \%$ for water and ethanol extract, respectively, for final weight loss percent. In brief, a temperature of $0-400^{\circ} \mathrm{C}$ is enough to completely break down zinc compounds with a good weight loss ratio.

$\mathrm{ZnO}$ NPs essentially consists of a 3D space that is periodically structured. X-rays must be dispersed by atoms of the sample. Basically, the dispersal of X-rays from arranged atoms creates diffractions in several directions, which are common for these atoms. Dspacing values from the achieved peaks enable mineral identification since every element has a set of $d$-spacings that do not match. This is simply accomplished by contrasting $d$-spacings with regular reference patterns.
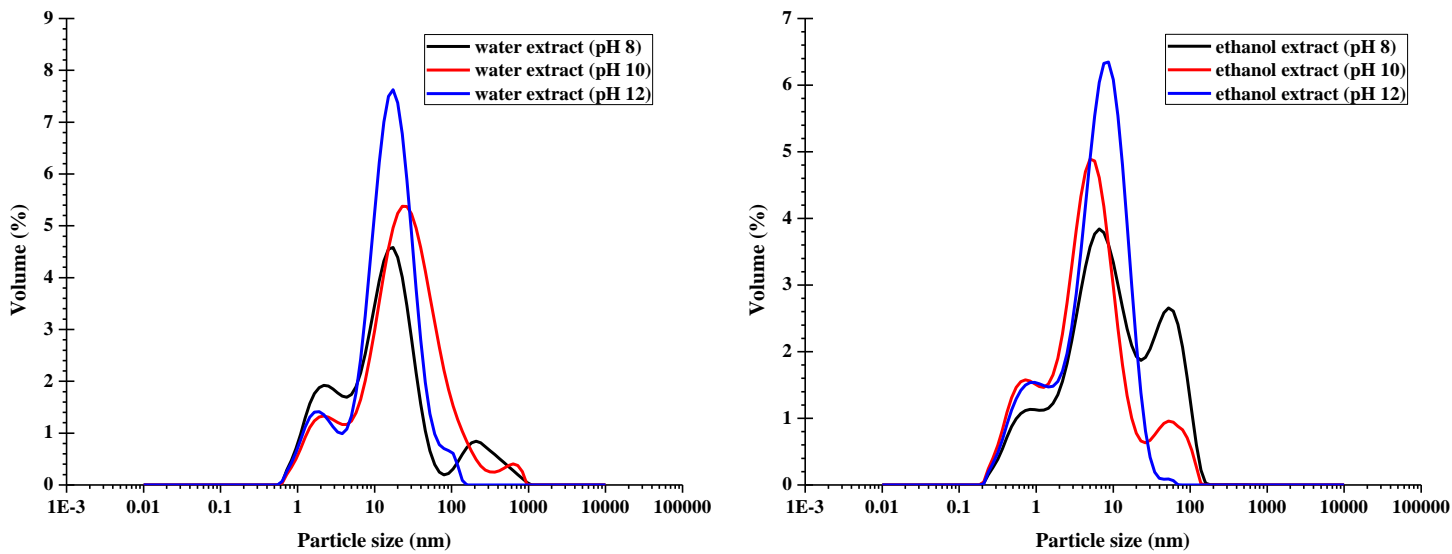

Figure 1. Particle size for synthesized $\mathrm{ZnO}$ NPs using both Psidium guajava L. extracts in water and ethanol at different $\mathrm{pH}$.
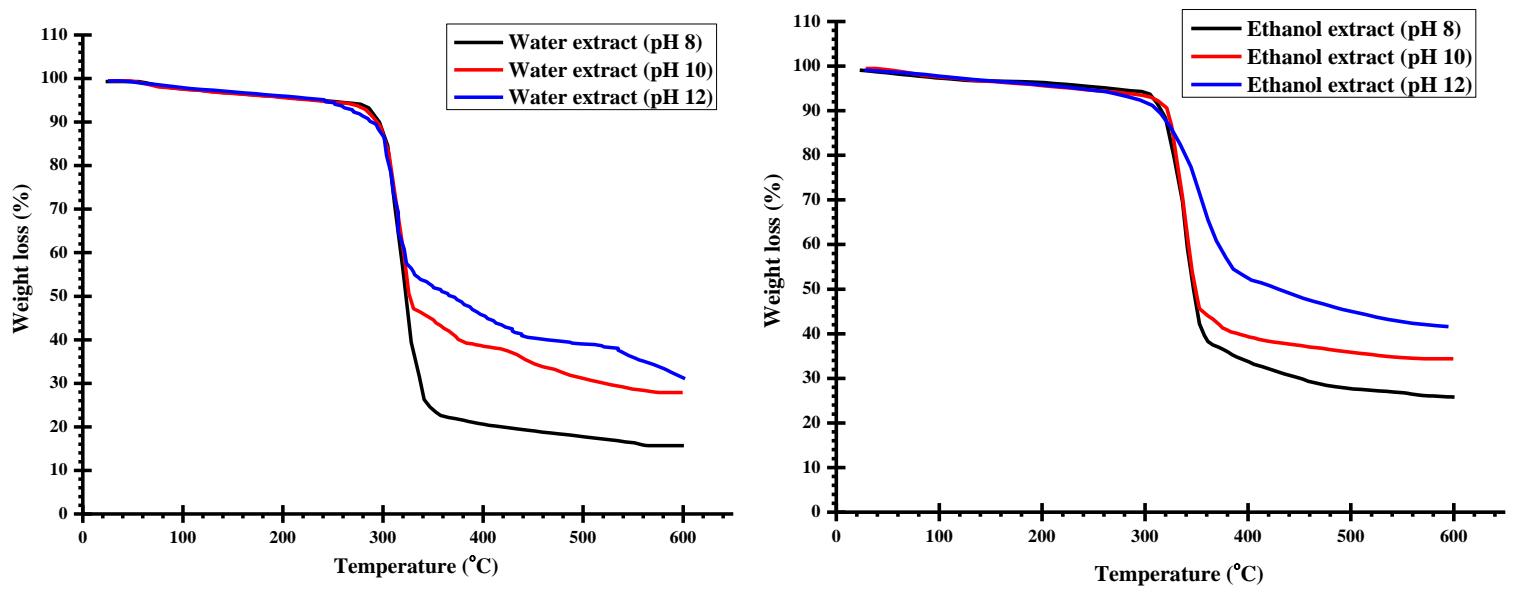

Figure 2. TGA for synthesized ZnO NPs using both Psidium guajava L. extracts in water and ethanol at different $\mathrm{pH}$.

The X-ray diagrams in Figure 3 display the same high intensity and width sequence for all the examined synthesized ZnO NPs. It reveals all prepared ZnO NPs with the same patterns under all $\mathrm{pH}$ medium, using both Psidium guajava L extract in water and alcohol. dSpacing values at 2 Theta positions (20; 32.09-32.21, 34.73-34.81, 36.53-36.69, 47.87-48.07, and 56.99-57.03) for synthesized $\mathrm{ZnO}$ NPs using Psidium guajava $\mathrm{L}$ extract in water and alcohol as a capping agent coincided with the results published by the many researchers in literature in terms of values $2.7,2.5,2.5,1.8$, and 1.6, respectively $[3,5,6,44]$.

The TEM images of Psidium guajava L extract in water and alcohol and synthesized $\mathrm{ZnO}$ NPs on various $\mathrm{pH}$ media $(8,10$, and 12$)$ are shown in Figure 4. TEM images are shown 
as a good distribution spherical shape. For Psidium guajava L, the TEM analysis indicates that the particles have small scatter sizes of 80 and $60 \mathrm{~nm}$, respectively, in the water and ethanol extract at $\mathrm{pH} 8$.

By comparison, in Psidium guajava L extracts in both water and ethanol, ZnO NPs were produced in nanoform. TEM images show that thin, spherical nanoparticles approximately $5 \mathrm{~nm}$ are agglomerates of small clusters during synthesis steps by increasing $\mathrm{pH}$ (until pH 12), as seen in Figure 4.

\subsection{Characterization of functionalized cotton fabric.}

3.2.1. Zinc content $(\%)$, and the ultraviolet protection factor (UPF)

The total content of zinc metal percent per $1 \mathrm{~g}$ treated cotton fabrics with synthesized $\mathrm{ZnO}$ NPs with/without biopolymers has been quantitatively determined by the flam atomic absorption method.
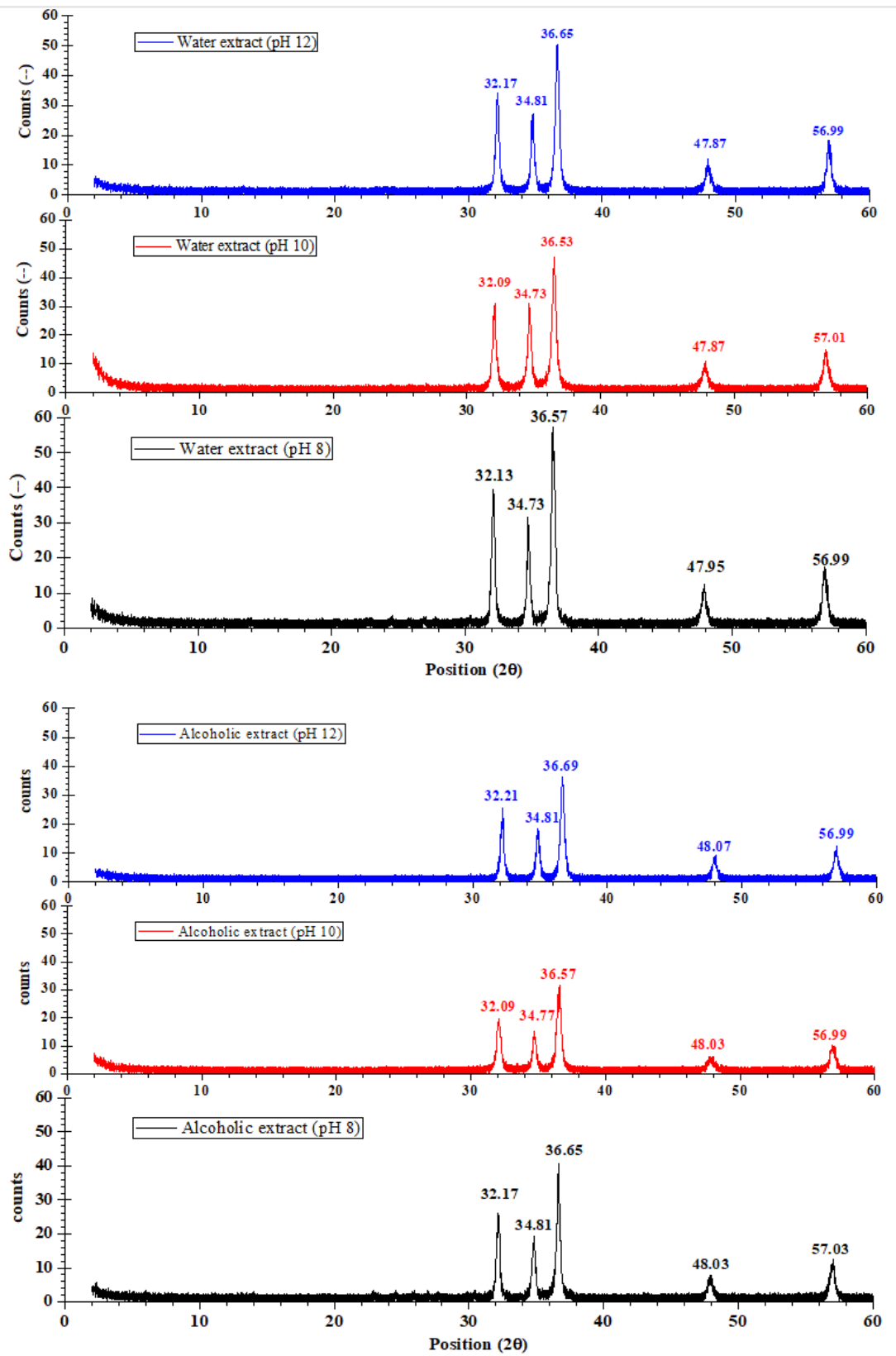

Figure 3. XRD for synthesized ZnO NPs using both Psidium guajava L. extracts in water and ethanol at different $\mathrm{pH}$. 

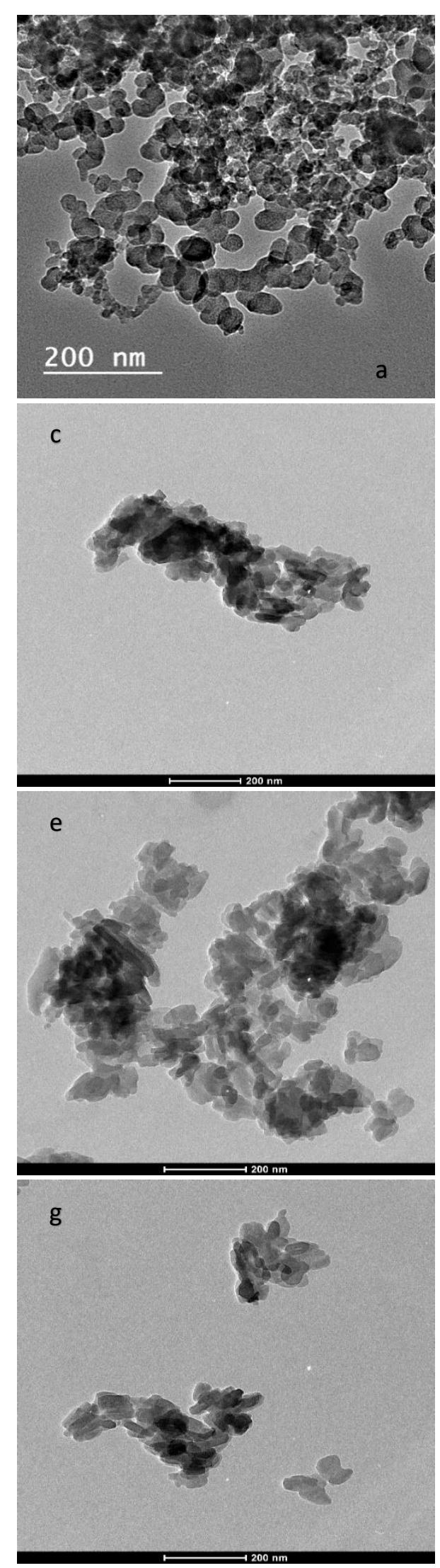

Figure 4. TEM image for synthesized ZnO NPs using both Psidium guajava L. extracts in water and ethanol at different pH. (a) Psidium guajava L.in water extract; (b) Psidium guajava L.in ethanol extract; (c) ZnO NPs in water extract at $\mathrm{pH} \mathrm{8,} \mathrm{(d)} \mathrm{ZnO} \mathrm{NPs} \mathrm{in} \mathrm{ethanol} \mathrm{extract} \mathrm{at} \mathrm{pH} 8$; (e) ZnO NPs in water extract at pH 10; (f) ZnO NPs in ethanol extract at $\mathrm{pH} 10 ;(\mathbf{g}) \mathrm{ZnO}$ NPs in water extract at $\mathrm{pH} 12 ;(\mathbf{h}) \mathrm{ZnO}$ NPs in ethanol extract at $\mathrm{pH} 12$.

The data show that the better binding efficiency was recorded to treated fabrics in the presence of chitosan over the pre-treated fabric with citric acid and sodium hypophosphite due to the ability of $\mathrm{ZnO}$ NPs to bind to the negative charge in the biopolymers. Therefore, https://biointerfaceresearch.com/ 
data provide that zinc percent uptake onto the treated fabric with ZnO NPs in chitosan presence is much higher than the treated fabrics with ZnO NPs only or with the other biopolymers. This is back to charge attraction between metals and negative charges of biopolymers molecules.

Further investigation for the treated fabric would determine the treated cotton fabric's ability to protect against ultraviolet waves by measuring the Ultraviolet protection Factor as $\mathrm{ZnO}$ NPs improve this property.

Therefore, the UPF values of untreated and treated cotton fabrics with synthesized $\mathrm{ZnO}$ NPs in the presence or absence of different biopolymer compounds were listed in Table 1. All treated fabrics have UPF values higher than untreated ones, which confirmed that $\mathrm{ZnO}$ NPs enhance the ability of cotton fabrics to protect from ultraviolet radiation and saving human skin from the harmful ultraviolet radiation

Data have shown that, compared to the untreated fabric, the higher the $\mathrm{Zn}$ content, the greater the UPF values. Results further demonstrate that the UPF values for fabrics treated with $\mathrm{ZnO}$ NPs in the presence of the biopolymer compound are better than those for those treated with ZnO NPs only, and UPF values typically increase as the $\mathrm{Zn}$ content $\%$ increased.

The UPF limits for UV-protection of the treated fabrics should be at least 40-50+, according to the report [47]. Thus, all treated fabrics with different formulations are associated with excellent UV protection even after washing.

Table 1. Zn content (\%) and ultraviolet protection factor (UPF) for treated fabrics with synthesized ZnO NPs with/without biopolymers.

\begin{tabular}{|c|c|c|c|c|}
\hline & \multirow{2}{*}{ extract } & \multirow{2}{*}{$\begin{array}{l}\text { Zn content }(\%) / 1 \\
\text { fabric }\end{array}$} & \multicolumn{2}{|c|}{ UPF } \\
\hline & & & Before washing & After washing \\
\hline \multicolumn{2}{|c|}{ Blank } & 0 & 0.1 & 0.1 \\
\hline \multirow{2}{*}{ ZnO NPs } & Water & 0.52 & 53.5 & 52.6 \\
\hline & Ethanol & 0.62 & 61.2 & 57.9 \\
\hline \multirow{2}{*}{ ZnO NPs/Alginate } & Water & 0.24 & 52.4 & 42.2 \\
\hline & Ethanol & 0.25 & 56.6 & 45.6 \\
\hline \multirow{2}{*}{$\mathrm{ZnO} \mathrm{NPs} / \mathrm{CMC}$} & Water & 0.20 & 49.8 & 42.5 \\
\hline & Ethanol & 0.23 & 53.4 & 42.3 \\
\hline \multirow{2}{*}{$\mathrm{ZnO}$ NPs/chitosan } & Water & 0.44 & 56.3 & 46.3 \\
\hline & Ethanol & 0.46 & 59.7 & 56.2 \\
\hline
\end{tabular}

3.2.2. Morphological behavior of treated fabric.

Figure 5 illustrates the SEM images and EDX spectra of the treated cotton fabrics with synthesized $\mathrm{ZnO}$ NPs with/without different biopolymers.

SEM images showed depositions of ZnO NPs onto the cotton surface, which provide the presence of the nanoparticles only or inside the deposited thin film of the biopolymer network. The SEM photos showed good deposition for the ZnO NPs used. However, the distribution of the $\mathrm{ZnO}$ NPs, homogeneousness, and thickness depends on the form of the biopolymers used.

In addition, the $\mathrm{Zn}$ elements on the treated materials were verified by the EDX spectrum. The Energy-Dispersion X-ray spectroscopy (EDX) technique was used to determine the Zn element's presence on the treated cotton surface. The EDX patterns detected carbon and oxygen elements on all the samples spectra, as well as $\mathrm{Zn}$ elements due to the presence of $\mathrm{ZnO}$ NPs. The spectra verified that the $\mathrm{ZnO}$ NPs were fixed to the surface of treated cotton fabrics.

It is observed that fabrics treated using the synthesized $\mathrm{ZnO}$ NPs acquire much roughness surfaces than those treated in the presence of any biopolymers. This reflects the 
importance of biopolymer in producing homogeneous distribution and penetration for the nanoparticles on treated fabrics' surface. Thus, treated fabric with synthesized ZnO NPs in the presence of any biopolymers provide a clear and smooth surface.

Furthermore, treated fabric with synthesized ZnO NPs in chitosan presence confirms the presence of more $\mathrm{ZnO}$ NPs content than the other two biopolymers (alginate or CMC). This observation was confirmed through EDX for treated fabric. The same result line is used to monitor $\mathrm{Zn}$ content for treated fabrics. SEM micrographs of treated fabrics with biopolymers indicate that surface morphology appears as a coated layer on the cotton surface and is characterized by being smoother and homogenous.
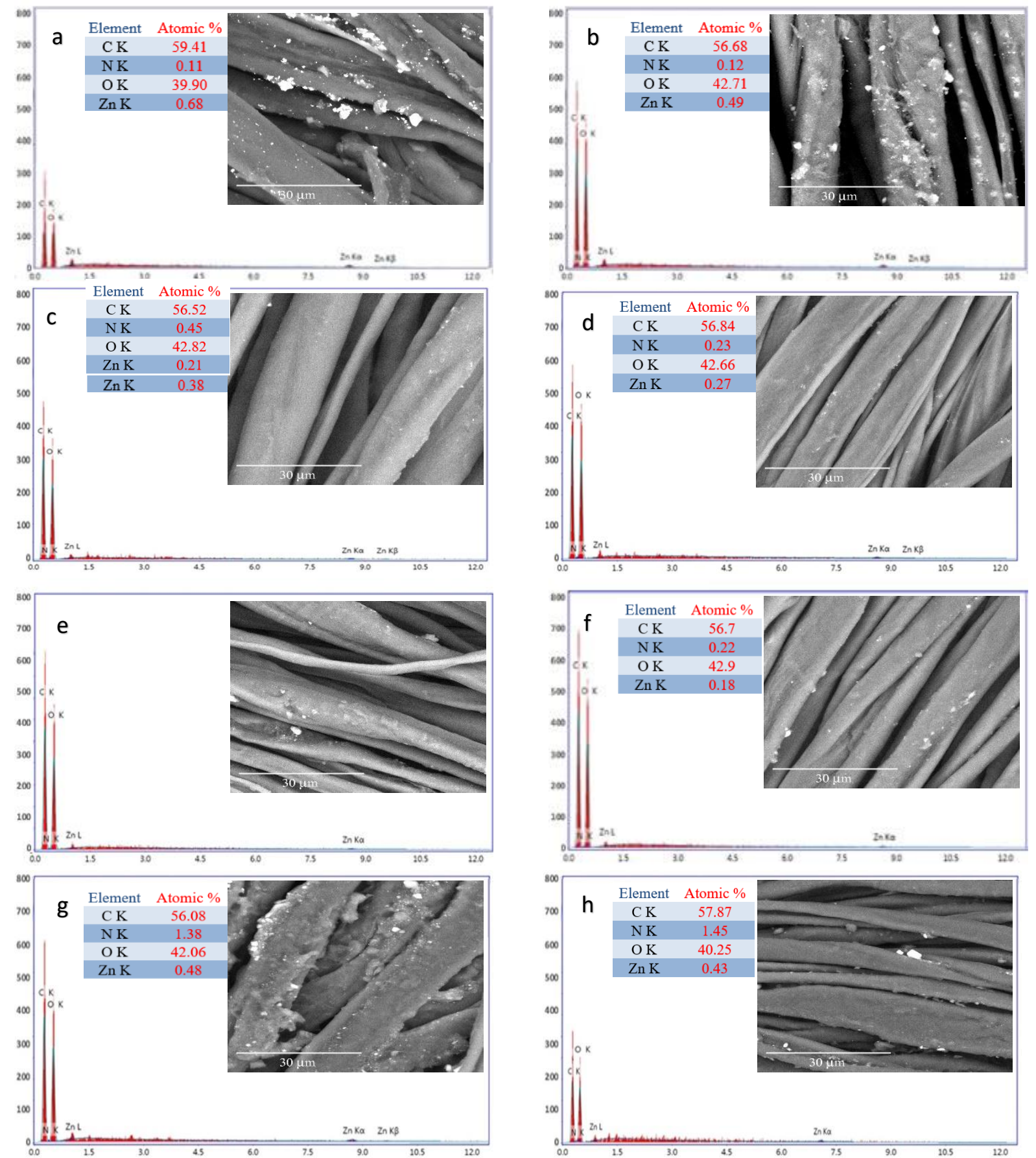

Figure 5. SEM and EDX images for treated cotton fabrics with synthesized ZnO NPs with/without biopolymer. (a) fabric with ZnO NPs (ethanol extract); (b) fabric with ZnO NPs (water extract); (c) fabric with ZnO

NPs (ethanol extract) and Alginate; (d) fabric with ZnO NPs (water extract) and Alginate; (e) fabric with ZnO NPs (ethanol extract) and CMC; (f) fabric with ZnO NPs (water extract) and CMC; (g) fabric with ZnO NPs (ethanol extract) and chitosan; (h) fabric with ZnO NPs (water extract) and chitosan. 


\subsubsection{Physical and mechanical properties.}

Treated cotton fabrics with Psidium guajava L. extracts and synthesized ZnO NPs with/without biopolymer have been checked for their mechanical and physical properties such as tensile strength, elongation at a break, bending length, air permeability, crease recovery angle, and surface roughness, and the results are recorded in Table 2.

From Table 2, it was clear that the crease recovery angle (CRA) increases dramatically as the roughness of the surface, air permeability, tensile strength, and elongation at break reduces after treatment with Psidium guajava L. extracts and ZnO NPs with/without biopolymer. This reveals that the examined ZnO NPs have been deeply absorbed into the microstructure of cotton fiber and responsible for these modifications, a thin film from the biopolymer used, deposited on the cotton's surface $[5,18,66,67]$. This deposited film cause was decreasing in ruggedness and increasing in air permeability values.

Also essential in determining the utility of the properties mentioned above was a precross-linking treatment with citric acid and sodium hypophosphite. The formation of covalent cross-linking links among nearby cellulosic chains would provide rigidity to the cotton structure during this pre-treatment. The citric acid and reaction would meanwhile chemically degrade the cellulosic chain in the cotton fiber.

Further investigation was going for investigation the crease recovery angle for treated fabrics in both warp and weft direction and bending length. The results provide that the crease recovery angle and bending length of all treated fabrics in presences of biopolymers have increased values compared with the untreated ones or treated fabrics in the absence of biopolymer materials. These results confirm that the biopolymer materials play an important role in enhancing the mechanical or physical properties. The crease recovery angle's key enhancement was possibly due to creating an extreme cotton structure network closely crosslinked by covalent chemical linkages between the cellulose chain and biopolymers $[5,18,66,67]$.

Table 2. Physical and mechanical properties for treated fabrics with synthesized ZnO NPs with/without biopolymer.

\begin{tabular}{|c|c|c|c|c|c|c|c|}
\hline & extract & $\begin{array}{l}\mathbf{R} \\
(\mu \mathrm{m})\end{array}$ & $\begin{array}{l}\text { Tensile } \\
\text { strength }\end{array}$ & $\begin{array}{l}\text { Elongation at } \\
\text { a break (\%) }\end{array}$ & $\begin{array}{l}\text { CRA } \\
\left(\mathbf{W}+\mathbf{F}^{\circ}\right)\end{array}$ & $\begin{array}{l}\text { Bending } \\
\text { length } \\
(\mathrm{cm})\end{array}$ & $\begin{array}{l}\text { Air permeability } \\
\left(\mathrm{cm}^{3} / \mathrm{cm}^{2} / \mathrm{s}\right)\end{array}$ \\
\hline \multicolumn{2}{|l|}{ Blank } & 21.45 & 152.12 & 39.21 & 198.19 & 2.05 & 21.87 \\
\hline \multirow{2}{*}{$\mathrm{ZnO}$ NPs } & Water & 23.24 & 123.51 & 34.81 & 223.17 & 2.36 & 95.53 \\
\hline & Ethanol & 23.61 & 121.34 & 44.04 & 225.84 & 2.38 & 95.46 \\
\hline \multirow{2}{*}{$\mathrm{ZnO}$ NPs/Alginate } & Water & 20.23 & 161.27 & 45.45 & 267.72 & 2.31 & 14.57 \\
\hline & Ethanol & 20.31 & 162.31 & 58.91 & 272.74 & 2.32 & 15.94 \\
\hline \multirow{2}{*}{$\mathrm{ZnO} \mathrm{NPs} / \mathrm{CMC}$} & Water & 20.56 & 162.34 & 45.76 & 270.62 & 2.25 & 16.89 \\
\hline & Ethanol & 20.54 & 162.45 & 58.96 & 273.57 & 2.28 & 16.59 \\
\hline \multirow{2}{*}{ ZnO NPs/chitosan } & Water & 19.78 & 164.65 & 46.41 & 285.45 & 2.41 & 18.78 \\
\hline & Ethanol & 19.67 & 164.78 & 59.81 & 291.04 & 2.52 & 20.43 \\
\hline
\end{tabular}

3.2.4. Self-cleaning activity.

Methylene blue (MB) is a popular thiazine dye used for photo-catalytical activity evaluation. The photo-catalytical transformation of MB by irradiated ZnO NPs can take place through two mechanisms: (1) oxidation process: complete mineralization of the substrate to carbon and mineral ion and (2) reduction process gives the leuco Methylene Blue shape (LMB) which is rapidly oxidized by the dissolved oxygen. (see below equations) [68] 


$$
\begin{aligned}
& \mathrm{MB}+\mathrm{n} \mathrm{h}_{\mathrm{vb}}+(\mathrm{OH}) \rightarrow \mathrm{CO}_{2}+\mathrm{NO}_{3}{ }^{-}+\mathrm{SO}_{4}{ }^{-2}+\mathrm{NH}_{4}{ }^{+} \\
& \mathrm{MB}+2 \mathrm{e}_{\mathrm{cb}}{ }^{-}+\mathrm{H}^{+} \rightarrow \mathrm{LMB} \\
& 2 \mathrm{LMB}+\mathrm{O}_{2} \rightarrow \mathrm{MB}+\mathrm{H}_{2} \mathrm{O}
\end{aligned}
$$

Furthermore, the presence of oxygen reduces the leuco MB formation due to two reasons: $i$ ) atmospheric $\mathrm{O}_{2}$ scavenged almost entirely the conduction band electrons; ( $\left.i i\right)$ the possible $\mathrm{MB}$ leuco form reacted immediately with $\mathrm{O}_{2}$ to give the original-colored $\mathrm{MB}$

Remove MB stains in the biopolymer matrix's presence and absence to evaluate the self-cleaning properties of the cotton textiles treated with the ZnO NPs was evaluated. The $\mathrm{ZnO}$ NPs-coated cotton fabrics' photocatalytic activity was investigated through their photodegradation of MB dye by measuring the stained fabric's color strength compared to the untreated one. By meaning, untreated and treated cotton fabrics have investigated their self-cleaning ability by adjusting methylene blue (MB) color intensity (K/S) before or after exposure to sunlight (UV).

The ZnO NPs are well known for their ability to create free radicals due to light photons' exposure, which are known as a self-cleaning property. The role in the color decomposition (or fading color) with the formed free radicals is due to its ability to changing the unsaturated chromophore to a saturated undyed molecule. This action is called color decomposition.

Figure 6 displays the K/S and K/S reduction (\%) of the untreated and treated cotton fabric with Psidium guajava L. extracts and synthesized $\mathrm{ZnO}$ NPs with/without biopolymer after UV exposure for 12, 24, and $48 \mathrm{hrs}$. Data shows that the discoloration in the treated fabrics is greater than in the untreated ones. Treated fabrics with ZnO NPs only without biopolymer were more discolored than those with either Psidium guajava L. extracts only or biopolymer. This may be due to the impregnation of $\mathrm{ZnO}$ NPs into the polymer network, which the main reason for increasing the coloring adsorption of the basic colorant onto the fabric surface and decreasing the effect of nanoparticle activity.

Also, treated fabrics with Psidium guajava L. extracts only increase the dying uptake and didn't provide self-cleaning activity as expected; thus, the dye discoloration values are almost identical with the untreated fabrics, while the presence of biopolymer with ZnO NPs on the cotton surface enhance the self-cleaning activity over the exposure time to UV. Furthermore, the impregnation of ZnO NPs in chitosan provides the highest dying uptake than the other two biopolymers (Alginate or CMC) due to the presence of two functional groups in the main structure of chitosan (hydroxyl and amine).

On the other hand, chitosan's presence shows higher values in dye discoloration, which is attributed to chitosan's role in the distribution of the nanoparticles in the treatment solution are better than the other two polymers. This homogenous distribution causes good distribution and covers the composite on the fabric surface, leading to more color decomposition efficiency.

Due to a photocatalytic degradation activity of the $\mathrm{ZnO}$ NPs deposited on the fabric surface, the MB stains' color intensities on the ZnO NPs-coated fabrics decreased dramatically. On the surface of the untreated fabric, the MB stains remained easily visible. The photocatalytic degradation properties depended on the presence and type of biopolymer used to impregnate $\mathrm{ZnO}$ NPs. 


\subsubsection{Antimicrobial properties.}

The antimicrobial activities of the treated fabrics with $\mathrm{ZnO}$ NPs with/without biopolymer coating were qualitatively and quantitatively demonstrated by using three types of microbes; gram-positive bacteria (Staphylococcus aureus), gram-negative bacteria (Escherichia coli), and fungus (Candida albicans).

The antimicrobial activity of treated cotton fabrics was shown in Figure 7 and Table 3 . The results show that there are no inhibition results on two types of bacteria and fungus tested on untreated cotton fabric (blank). Compared to the three types of studied microbes, treated fabrics with both Psidium guajava L. extracts in water and ethanol show substantially increased antibacterial activity, which is provided by measuring the inhibition zone area. The data provides good inhibition zone area (including tested fabric area $\left(78.6 \mathrm{~mm}^{2}\right)$ ) recorded for treated fabric with water extract as $187.76 \pm 0.15,280.72 \pm 0.23,278.96 \pm 0.17 \mathrm{~mm}^{2}$ and for treated fabric with ethanol extract as $189.73 \pm 0.21,327.37 \pm 0.42,204.63 \pm 0.36 \mathrm{~mm}^{2}$ for $E$. coli, S. aureus, and C. albicans, respectively.

The presence of phenolic acid and flavonoids in Psidium guajava L extract is the cause for this successful activity. Compared to gram-positive bacteria, treated fabrics are higher effective than Gram-negative bacteria, owing to the variations in the composition of both the studied bacteria strain's cell walls. These compounds also serve as an antifungal substance since they suppress ergosterol, the fungal cell membrane's key component [69-71].

Treated fabrics with synthesized $\mathrm{ZnO}$ NPs with/without biopolymer against both bacteria and fungi provide antimicrobial behavior greater than untreated fabric. The antimicrobial effect increased base on the biopolymer used. The presence of chitosan with nanoparticles provides more antimicrobial effect than other both polymer and nanoparticles only. That is because chitosan provides a good antimicrobial due to amino groups, which plays an excellent role in attacking the cell membrane of microbes [66]. The carboxyl group present in alginate provides antimicrobial properties but less than the amino group present in chitosan. Furthermore, ZnO NPs provide antimicrobial properties which imparted to cotton fabrics and confirmed by this method.

The difference in the influence on various microbes in each of these materials was further due to the cell walls' composition differences. The gram-positive bacteria are distinguished because each cell membrane, enclosed with a thick and porous cell wall, allows some bioactive components to spread through this. Instead, gram-negative bacteria consist of three different layers containing several bioactive elements.

$\mathrm{ZnO}$ NPs are successfully interacted by the coating process with the cells of the bacteria. The biopolymers engaged in the coating have good diffusion and stabilization of $\mathrm{ZnO}$ NPs on the cotton surface, reducing the capacity to tie bacterial cells onto the cotton surface $[6,19,20,72]$.

Besides, treated cotton textiles with synthesized $\mathrm{ZnO}$ NPs with/without biopolymer have excellent antibacterial properties than the untreated ones. The antibacterial reduction percent decreased as the treated fabrics' washing cycles were increased $(5,10,15$, and 20 cycles) (Table 3 ). This decrease in reduction percent is varied regarding the biopolymer used in the treatment. The durability of the fabrics being treated in the process provides an excellent antimicrobial property against tested microbes even after different washing cycles. The bacterial reduction percent provides a reduction of up to $93 \%$ after 20 washing cycles for treating fabrics with $\mathrm{ZnO}$ NPs/chitosan. 

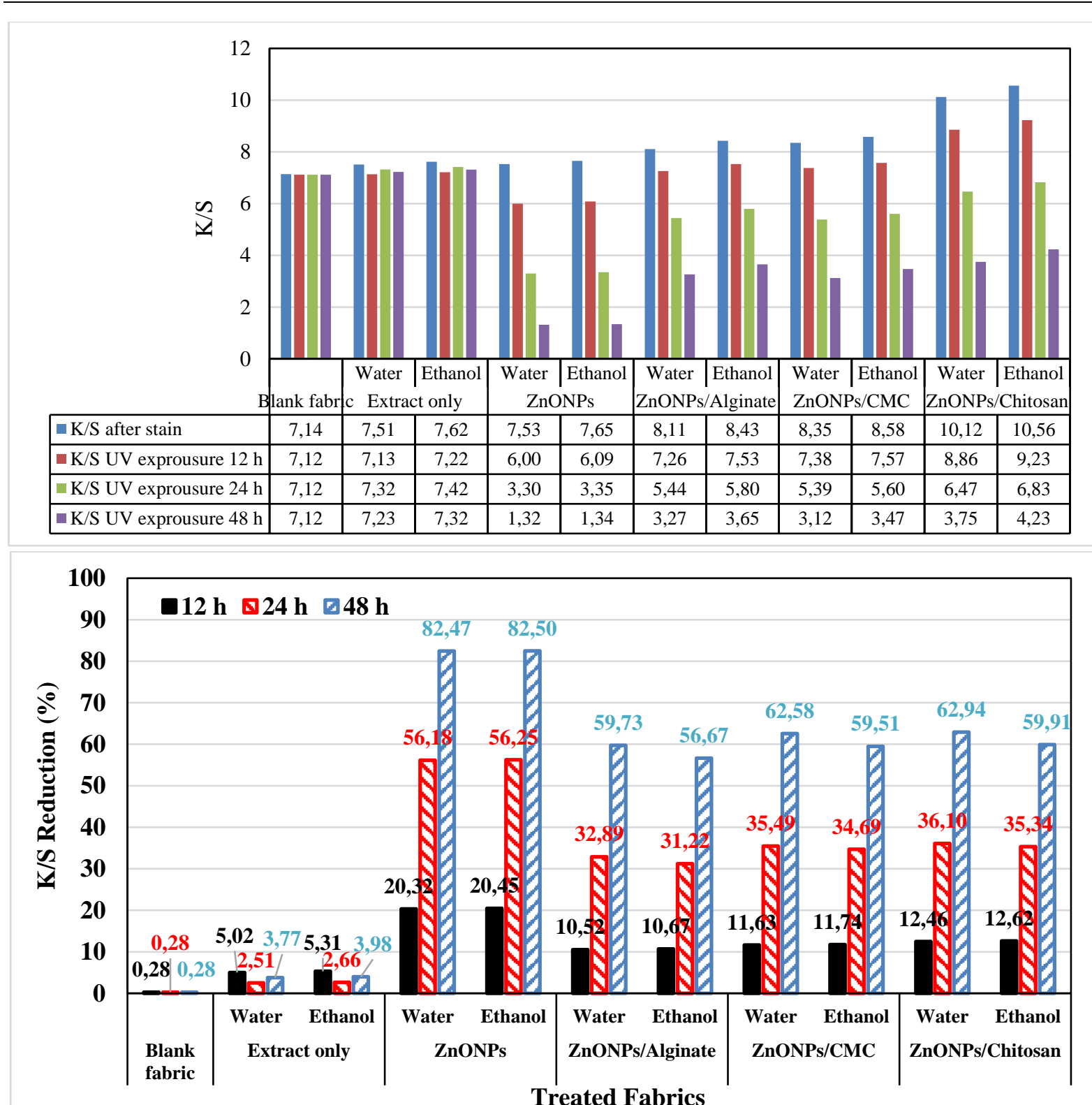

Figure 6. Self-cleaning activity expressed as K/S (a) and K/S reduction (\%) (b) for treated fabrics with Psidium guajava L. extracts and synthesized ZnO NPs with/without biopolymer after UV exposure for 12, 24, and 48 hrs.

\subsubsection{Contact angle and wettability.}

There are two parameters analyzed to explain the interactions of fabric surface with water, i) the contact angle and ii) the wettability time. The angle of contact between a droplet and the fabric surface can be described as the contact angle. When the water droplet obtains a small contact angle at the surface, the surface is then considered hydrophilic and quickly moisturized, and the water droplet spreads. The surface area between the droplet and the surface of the fabric is thus rising. On the other hand, the surface is called hydrophobic. A water droplet on the fabric surface forms a large contact angle; the surface tends to repel water. Treated fabrics were analyzed by calculating the contact angle and wettability time, and the results are listed in The biopolymer's presence as a carrier for good distribution of $\mathrm{ZnO}$ NPs in their network decreased the contact angle than treated fabric with ZnO NPs only. This is due to the thin layer of film on the treated cotton surface, which relatively filled the superficial fibers' cavities and slightly enhanced the hydrophobicity. As both biopolymers 
(alginate and $\mathrm{CMC}$ ) are soluble in water, they improve the hydrophilicity property more than chitosan (water-insoluble biopolymer).

Table 4.
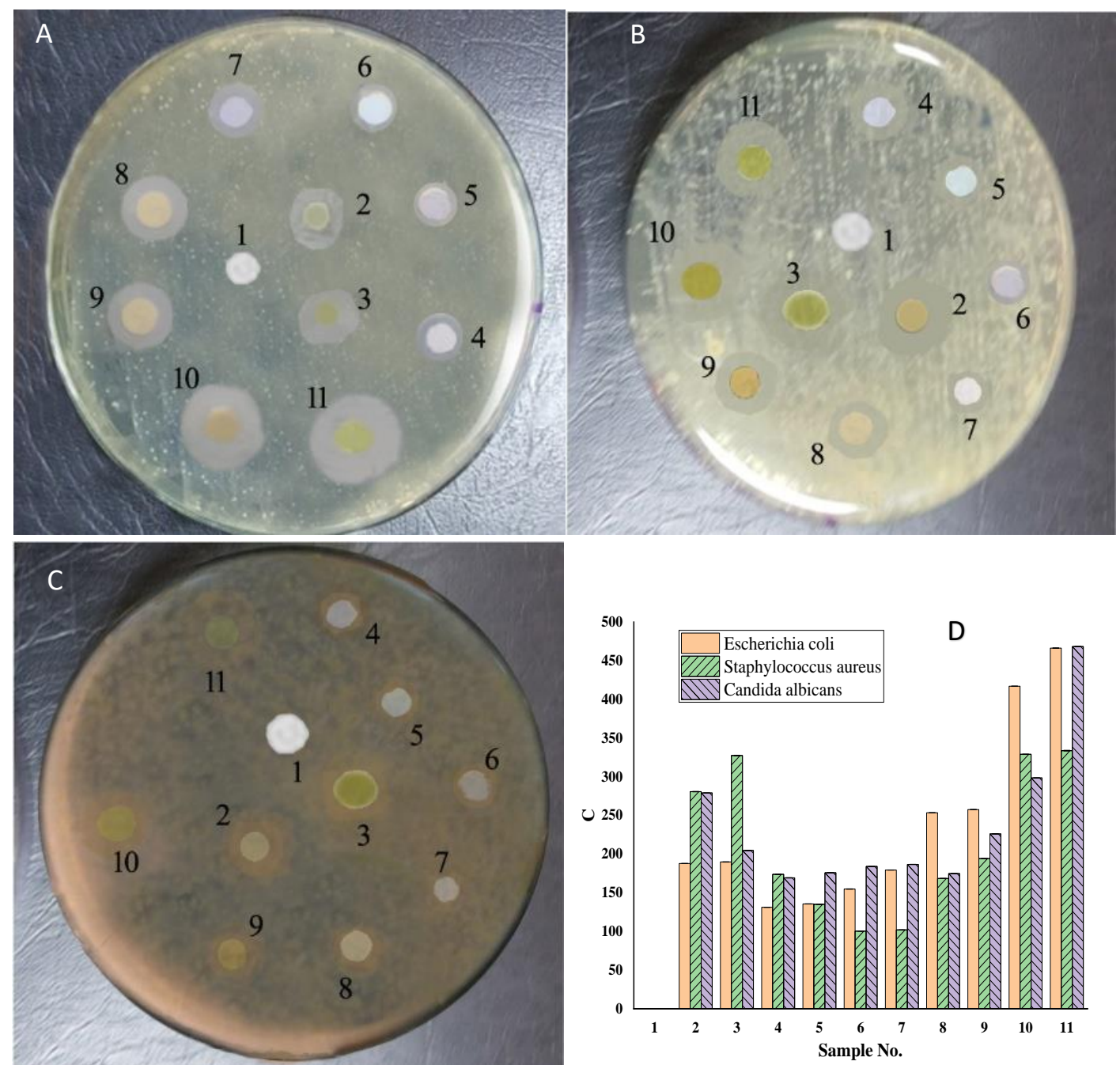

Figure 7. Antibacterial activity of treated fabrics with Psidium guajava L. extracts and synthesized ZnO NPs with/without biopolymer against (a) E. coli (gram-negative bacterium); (b) S. aureus (gram-positive bacterium); (c) C. albicans (fungus); (d) calculated area of inhibition zone (1) untreated fabric; (2) treated fabrics with Psidium guajava L. in water extract; (3) treated fabrics with Psidium guajava $\mathrm{L}$. in ethanol extract; (4) treated fabrics with $\mathrm{ZnO}$ from water extract; (5) treated fabrics with $\mathrm{ZnO}$ from the ethanol extract; (6) treated fabrics with $\mathrm{ZnO} /$ Alginate from water extract; (7) treated fabrics with $\mathrm{ZnO} /$ Alginate from the ethanol extract; (8) treated fabrics with $\mathrm{ZnO} / \mathrm{CMC}$ from water extract; (9) treated fabrics with $\mathrm{ZnO} / \mathrm{CMC}$ from the ethanol extract; (10) treated fabrics with $\mathrm{ZnO} /$ Chitosan from water extract; (11) treated fabrics with $\mathrm{ZnO} /$ Chitosan from the ethanol extract.

Table 3. Microbial reduction $\%$ of untreated and treated cotton fabrics.

\begin{tabular}{|c|c|c|c|c|c|c|c|c|c|c|c|c|c|c|c|c|}
\hline \multirow{4}{*}{$\begin{array}{c}\text { Treated } \\
\text { fabric } \\
\text { with }\end{array}$} & \multirow{4}{*}{$\begin{array}{c}\text { Extraction } \\
\text { process }\end{array}$} & \multicolumn{15}{|c|}{ Microbial Reduction \% } \\
\hline & & \multicolumn{5}{|c|}{ E. coli (ATCC 25922) } & \multicolumn{5}{|c|}{ S. aureus (ATCC 29213) } & \multicolumn{5}{|c|}{ C. albicans (ATCC 10231) } \\
\hline & & \multirow{2}{*}{\begin{tabular}{|c|} 
before \\
washing
\end{tabular}} & \multicolumn{4}{|c|}{ after washing cycles } & \multirow{2}{*}{\begin{tabular}{|c|} 
before \\
washing \\
\end{tabular}} & \multicolumn{4}{|c|}{ after washing cycles } & \multirow{2}{*}{$\begin{array}{c}\text { before } \\
\text { washing }\end{array}$} & \multicolumn{4}{|c|}{ after washing cycles } \\
\hline & & & 5 & 10 & 15 & 20 & & 5 & 10 & 15 & 20 & & 5 & 10 & 15 & 20 \\
\hline \multicolumn{2}{|c|}{ Blank fabric } & 0 & 0 & 0 & 0 & 0 & 0 & 0 & 0 & 0 & 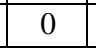 & 0 & 0 & 0 & 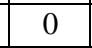 & 0 \\
\hline \multirow{2}{*}{$\begin{array}{c}\text { Extract } \\
\text { only } \\
\end{array}$} & Water & 62.91 & 51.27 & 31.13 & 29.80 & 28.23 & 76.18 & 62.08 & 37.66 & 36.05 & 34.14 & 56.53 & 46.08 & 27.98 & 26.79 & 25.38 \\
\hline & Etha & 66.77 & 54.42 & 40.20 & 38.49 & 36.45 & 87.21 & 71.06 & 62.48 & 59.80 & 56.64 & 61.31 & 49.97 & 43.94 & 42.07 & 39.85 \\
\hline \multirow{2}{*}{$\mathrm{ZnO}$} & & & 7 & & & 6 & 72 & 77 & 6 & 5 & 6 & & 3 & & & 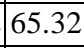 \\
\hline & Eth & 86.02 & 79.84 & 72.73 & 71.87 & 70.86 & 96.23 & 88.16 & 83.87 & 82.53 & 80.95 & 83.28 & 77.62 & 74.60 & 5 & 72.55 \\
\hline \multirow{2}{*}{$\begin{array}{c}\mathrm{ZnO} / \\
\text { Alginate }\end{array}$} & ter & 84.67 & 81.76 & 76.73 & 76.39 & 76.00 & 87.99 & 84.46 & 78.36 & 77.96 & 77.48 & 83.08 & 80.46 & 75.94 & 75.64 & 75.29 \\
\hline & Ethanol & 85.64 & 82.55 & 79.00 & 78.57 & 78.06 & 90.75 & 86.71 & 84.56 & 83.90 & 83.11 & 84.27 & 81.44 & 79.93 & 79.46 & 78.91 \\
\hline \multirow{2}{*}{$\begin{array}{l}\mathrm{ZnO} / \\
\mathrm{CMC}\end{array}$} & & 84.38 & 80.02 & 72.46 & 71.96 & 71.37 & 89.36 & 84.07 & 74.91 & 74.30 & 73.59 & 81.99 & 78.07 & 71.28 & 70.83 & 70.30 \\
\hline & Ethanol & 85.83 & 81.19 & 75.86 & 75.22 & 74.46 & 93.49 & 87.44 & 84.22 & 83.21 & $\mid 82.03$ & 83.78 & 79.53 & 77.27 & 76.56 & 75.73 \\
\hline
\end{tabular}


\begin{tabular}{l|c|c|c|c|c|c|c|c|c|c|c|c|c|c|c|c|c|c|c|c|c|} 
ZnO/ & Water & 96.48 & 95.09 & 90.45 & 82.69 & 82.61 & 99.74 & 97.41 & 94.49 & 92.58 & 90.32 & 96.20 & 94.41 & 93.54 & 91.97 & 90.10 \\
\hline
\end{tabular} \begin{tabular}{c|c|c|c|c|c|c|c|c|c|c|c|c|c|c|c|c|c|c|c|} 
Chitosan & Ethanol & 98.48 & 98.24 & 91.40 & 89.00 & 86.16 & 99.66 & 99.33 & 98.43 & 97.48 & 96.99 & 98.41 & 97.94 & 96.65 & 94.13 & 93.16
\end{tabular} The biopolymer's presence as a carrier for good distribution of ZnO NPs in their network decreased the contact angle than treated fabric with ZnO NPs only. This is due to the thin layer of film on the treated cotton surface, which relatively filled the superficial fibers' cavities and slightly enhanced the hydrophobicity. As both biopolymers (alginate and $\mathrm{CMC}$ ) are soluble in water, they improve the hydrophilicity property more than chitosan (water-insoluble biopolymer).

Table 4. Contact angle, wettability time, and drop photo image for treated cotton fabrics.

\begin{tabular}{|c|c|c|c|c|c|c|c|}
\hline \multirow{3}{*}{\multicolumn{2}{|c|}{ Treated fabric with }} & \multicolumn{6}{|c|}{ Synthesized ZnO NPs with } \\
\hline & & \multicolumn{3}{|c|}{ Water extract } & \multicolumn{3}{|c|}{ Ethanol Extract } \\
\hline & & $\begin{array}{c}\text { Wettability } \\
\text { time (sec) }\end{array}$ & $\begin{array}{r}\text { Contact } \\
\text { angle }\left({ }^{\circ}\right)\end{array}$ & Drop photo image & $\begin{array}{l}\text { Wettability } \\
\text { time (sec) }\end{array}$ & $\begin{array}{l}\text { Contact } \\
\text { angle }\left({ }^{\circ}\right)\end{array}$ & Drop photo image \\
\hline \multicolumn{2}{|c|}{ Blank } & 2 & 0 & & 2 & 0 & \\
\hline \multirow[b]{2}{*}{$\mathrm{ZnO} \mathrm{NPs}$} & $\begin{array}{c}\text { Before } \\
\text { washing }\end{array}$ & 90 & $\begin{array}{c}126.52 \pm \\
2.38 \\
\end{array}$ & & 90 & $\begin{array}{c}112.54 \pm \\
6.63 \\
\end{array}$ & \\
\hline & $\begin{array}{c}\text { After } \\
\text { washing }\end{array}$ & 30 & $\begin{array}{c}118.50 \pm \\
2.02\end{array}$ & & 60 & $\begin{array}{c}102.42 \pm \\
5.64\end{array}$ & \\
\hline \multirow{2}{*}{$\begin{array}{c}\mathrm{ZnO} \\
\text { NPs/Alginat } \\
\mathrm{e}\end{array}$} & $\begin{array}{c}\text { Before } \\
\text { washing }\end{array}$ & 30 & $\begin{array}{c}133.32 \pm \\
5.51\end{array}$ & & 60 & $\begin{array}{c}107.35 \pm \\
1.82 \\
\end{array}$ & \\
\hline & $\begin{array}{c}\text { After } \\
\text { washing }\end{array}$ & 15 & $\begin{array}{c}128.66 \pm \\
4.96\end{array}$ & & 15 & $\begin{array}{c}100.09 \pm \\
1.64\end{array}$ & \\
\hline \multirow{2}{*}{$\begin{array}{c}\mathrm{ZnO} \\
\mathrm{NPs} / \mathrm{CMC}\end{array}$} & $\begin{array}{c}\text { Before } \\
\text { washing }\end{array}$ & 90 & $\begin{array}{c}136.88 \pm \\
3.09 \\
\end{array}$ & & 60 & $89.86 \pm 4.25$ & \\
\hline & $\begin{array}{c}\text { After } \\
\text { washing }\end{array}$ & 30 & $\begin{array}{c}132.54 \pm \\
2.78\end{array}$ & & 15 & $80.85 \pm 3.83$ & \\
\hline \multirow{2}{*}{$\begin{array}{c}\mathrm{ZnO} \\
\text { NPs/chitosan }\end{array}$} & $\begin{array}{c}\text { Before } \\
\text { washing }\end{array}$ & 210 & $\begin{array}{c}134.03 \pm \\
3.18 \\
\end{array}$ & & 120 & $\begin{array}{c}111.39 \pm \\
9.81 \\
\end{array}$ & \\
\hline & $\begin{array}{c}\text { After } \\
\text { washing }\end{array}$ & 60 & $\begin{array}{c}131.73 \pm \\
3.02\end{array}$ & & 30 & $\begin{array}{c}107.96 \pm \\
9.32\end{array}$ & \\
\hline
\end{tabular}

Furthermore, as the contact angle of treated fabric increases compared to blank fabric, the wettability time also increases. The excellent observation and the wetting performance for treated fabric with ZnO NPs in chitosan presence provide a higher time than other treated fabrics even with $\mathrm{ZnO}$ NPs. This phenomenon is due to the thin layer of film on the treated fabric surface, which relatively filled the superficial fibers' cavities and enhanced the fibrous surface with higher rough morphology, causing increased hydrophobicity.

The contact angles for treated fabrics were reported after washing to analyze the treated cotton fabrics' resilience. It is observed that the contact angle and wettability time was decreased significantly. Another investigation treated fabrics with ZnO NPs in the presence of chitosan biopolymer, providing a good wettability performance even after washing. From this analysis, a composite coating on the fabric's surface was implemented to achieve a specific water repellence, weather resistance. Therefore, depending on the coating substance, superhydrophobic fabrics can be used in water-oil applications.

\section{Conclusions}

Psidium guava leaf extract can be used as a reducing agent to synthesize zinc oxide nanoparticles as a green route method instead of a chemical method that uses hazardous chemicals because it has many bioactive compounds such as phenols, flavonoids. Psidium 
Guava Leave was extracted using two solvents (water and ethanol). Both of them can be used as reducing agents for the synthesis of zinc oxide nanoparticles.

The synthesized ZnO NPs was studied at various pHs. The particle size of synthesized $\mathrm{ZnO}$ NPs was analyzed. It was found that, by increasing the $\mathrm{pH}$ medium, the synthesized $\mathrm{ZnO}$ NPs particles decreased. It is also noted that the particle size of the synthesized $\mathrm{ZnO}$ NPs with Psidium guajava L. extract in water is higher than those in alcohol at different $\mathrm{pH}$ $(8,10$, and 12) medium. Moreover, for shaping ZnO NPs in both extracts, $\mathrm{pH} 12$ proved to be an excellent medium. TEM images show that thin, spherical nanoparticles approximately $5 \mathrm{~nm}$ are agglomerates of small clusters during synthesis steps by increasing $\mathrm{pH}$ (until $\mathrm{pH}$ 12).

The treated cotton fabric with $\mathrm{ZnO}$ NPs and $\mathrm{ZnO}$ NPs impregnated with biopolymers (Alginate, chitosan, and carboxymethyl cellulose) showed that the higher the $\mathrm{Zn}$ content, the greater the UPF values. The UPF values and antimicrobial activity for fabrics treated with $\mathrm{ZnO}$ NPs in the presence of the biopolymer compound are better than those treated with $\mathrm{ZnO}$ NPs only.

Untreated and treated cotton fabrics have investigated their self-cleaning ability by adjusting methylene blue (MB) color intensity $(\mathrm{K} / \mathrm{S})$ before or after exposure to sunlight (UV), and it was found that the discoloration in the treated fabrics is greater than in the untreated ones. Treated fabrics with ZnO NPs only without biopolymer were more discolored than those with either Psidium guajava L. extracts or biopolymer.

\section{Funding}

This research received no external funding.

\section{Acknowledgments}

The authors are gratefully thankful to acknowledge National Research Centre (NRC) for the facilities provided and the Faculty of Applied Arts, Benha University.

\section{Conflicts of Interest}

The authors declare no conflict of interest.

\section{References}

1. Sriram, T.; Pandidurai, V. Synthesis of silver nanoparticles from leaf extract of Psidium guajava and its antibacterial activity against pathogens. Int. J. Curr. Microbiol. App. Sci 2014, 3, 146-152.

2. Yuvakkumar, R.; Suresh, J.; Nathanael, A.J.; Sundrarajan, M.; Hong, S.I. Novel green synthetic strategy to prepare $\mathrm{ZnO}$ nanocrystals using rambutan (Nephelium lappaceum L.) peel extract and its antibacterial applications. Materials Science and Engineering: C 2014, 41, 17-27, http://doi.org/10.1016/j.msec.2014.04.025.

3. Mohamed AL, Hassabo AG, Review of silicon-based materials for cellulosic fabrics with functional applications, Journal of Textiles, Coloration and Polymer Science, 2019; 16: 139-157. https://doi.org/10.21608/JTCPS.2019.18580.1030.

4. Mohamed, A.L.; El-Naggar, M.E.; Shaheen, T.I.; Hassabo, A.G. Novel nano polymeric system containing biosynthesized core shell silver/silica nanoparticles for functionalization of cellulosic based material. Microsystem Technologies 2016, 22, 979-992, http://doi.org/10.1007/s00542-015-2776-0.

5. El-Naggar, M.E.; Hassabo, A.G.; Mohamed, A.L.; Shaheen, T.I. Surface modification of SiO2 coated ZnO nanoparticles for multifunctional cotton fabrics. J. Colloid Interface Sci. 2017, 498, 413-422, http://dx.doi.org/10.1016/j.jcis.2017.03.080. 
6. Ibrahim, N.A.; Nada, A.A.; Hassabo, A.G.; Eid, B.M.; Noor El-Deen, A.M.; Abou-Zeid, N.Y. Effect of different capping agents on physicochemical and antimicrobial properties of $\mathrm{ZnO}$ nanoparticles. Chemical Papers 2017, 71, 1365-1375, http://doi.org/10.1007/s11696-017-0132-9.

7. Mohamed, A.L.; El-Naggar, M.E.; Shaheen, T.I.; Hassabo, A.G. Laminating of chemically modified silan based nanosols for advanced functionalization of cotton textiles. Int. J. Biol. Macromol. 2017, 95, 429-437, https://doi.org/10.1016/j.ijbiomac.2016.10.082.

8. Mohamed, A.L.; Hassabo, A.G. Composite material based on pullulan/silane/ZnO-NPs as pH, thermo-sensitive and antibacterial agent for cellulosic fabrics. Advances in Natural Sciences: Nanoscience and Nanotechnology 2018, 9, 045005, https://doi.org/10.1088/2043-6254/aaeee0.

9. Hassabo, A.G.; El-Naggar, M.E.; Mohamed, A.L.; Hebeish, A.A. Development of multifunctional modified cotton fabric with tri-component nanoparticles of silver, copper and zinc oxide. Carbohydr. Polym. 2019, 210, 144-156, https://doi.org/10.1016/j.carbpol.2019.01.066.

10. Hassabo, A.G.; Mohamed, A.L. Novel flame retardant and antibacterial agent containing mgo nps, phosphorus, nitrogen and silicon units for functionalise cotton fabrics. Biointerface Research in Applied Chemistry 2019, 9 , 4272-4278, https://doi.org/10.33263/BRIAC95.272278.

11. Hassabo, A.G.; Shaarawy, S.; Mohamed, A.L.; Hebiesh, A. Multifarious cellulosic through innovation of highly sustainable composites based on Moringa and other natural precursors. Int. J. Biol. Macromol. 2020, 165, 141155, https://doi.org/10.1016/j.ijbiomac.2020.09.125.

12. Mohamed, A.L.; Hassabo, A.G. Cellulosic fabric treated with hyperbranched polyethyleneimine derivatives for improving antibacterial, dyeing, $\mathrm{pH}$ and thermo-responsive performance. Int. J. Biol. Macromol. 2021, 170, 479-489, https://doi.org/10.1016/j.ijbiomac.2020.12.198.

13. Subhasree, R.S.; Selvkumar, D.; Kumar, N.S. Hydrothermal mediated synthesis of zno nanorods and their antibacterial properties. Letters in Applied NanoBioScience 2012, 1, 2-7, https://doi.org/10.33263/LIANBS11.27.

14. Joshi, N.C.; Malik, S.; Gururani, P. Utilization of Polypyrrole/ZnO Nanocomposite in the Adsorptive Removal of $\mathrm{Cu} 2+, \mathrm{Pb} 2+$ and $\mathrm{Cd} 2+$ ions from wastewater. Letters in Applied NanoBioScience 2021, 10, 2339-2351, https://doi.org/10.33263/LIANBS103.23392351.

15. Abidi, N.; Hequet, E.; Tarimala, S. Functionalization of Cotton Fabric with Vinyltrimethoxysilane. Textile Research Journal 2007, 77, 668-674, https://doi.org/10.1177/0040517507080621.

16. Abidi, N.; Cabrales, L.; Hequet, E. Functionalization of a Cotton Fabric Surface with Titania Nanosols: Applications for Self-Cleaning and UV-Protection Properties. ACS Applied Materials \& Interfaces 2009, 1, 2141-2146, http://doi.org/10.1021/am900315t.

17. Gao, D.; Lyu, L.; Lyu, B.; Ma, J.; Yang, L.; Zhang, J. Multifunctional cotton fabric loaded with Ce doped ZnO nanorods. Mater. Res. Bull. 2017, 89, 102-107, https://doi.org/10.1016/j.materresbull.2017.01.030.

18. Mohamed, A.; Hassabo, A.; Nada, A.; Abou-Zeid, N.Y. Properties of cellulosic fabrics treated by waterrepellent emulsions. Indian Journal of Fibre and Textile Research 2017, 42, 223-229.

19. Mohamed, A.L.; Hassabo, A.G.; Shaarawy, S.; Hebeish, A. Benign development of cotton with antibacterial activity and metal sorpability through introduction amino triazole moieties and AgNPs in cotton structure pretreated with periodate. Carbohydr. Polym. 2017, 178, 251-259, http://doi.org/10.1016/j.carbpol.2017.09.024.

20. Aboelnaga, A.; Shaarawy, S.; Hassabo, A.G. Polyaconitic acid/functional amine/azo dye composite as a novel hyper-branched polymer for cotton fabric functionalization. Colloids Surf. B. Biointerfaces 2018, 172, 545-554, https://doi.org/10.1016/j.colsurfb.2018.09.012.

21. Hassabo, A.G.; Sharaawy, S.; Mohamed, A.L. Saturated fatty acids derivatives as assistants materials for textile processes. Journal of Textile Science \& Fashion Technology 2018, 1, 000516, http://dx.doi.org/10.33552/JTSFT.2018.01.000516.

22. Elshemy, N.S.; Nassar, S.H.; El-Taieb, N.M.; Shakour, A.A.A.; Elmekawy, A.M.; Hassabo, A.G. Effect of different fabrics types on the adsorption of air pollution in residential and industrial atmosphere in cairo-egypt. Letters in Applied NanoBioScience 2019, 9, 682-691, https://doi.org/10.33263/LIANBS84.682691.

23. Hassabo, A.G.; Mohamed, A.L. Enhancement of Thermo-Regulating Textile Materials Using Phase Change Material (PCM). Evolution in Polymer Technology Journal 2019, 2, 180009.

24. Khattab, T.A.; Mohamed, A.L.; Hassabo, A.G. Development of durable superhydrophobic cotton fabrics coated with silicone/stearic acid using different cross-linkers. Mater. Chem. Phys. 2020, 249, 122981, https://doi.org/10.1016/j.matchemphys.2020.122981. 
25. Hussien, A.M.; hassan, s.; Saleh, S.M.; Ismail, E.E. Ultraviolet protection of Cotton Fabrics and their Blends using natural plant extracts by printing style. Egyptian Journal of Chemistry 2020, 63, 3-4, http://doi.org/10.21608/ejchem.2020.23842.2419.

26. Ibrahim, H.I.; Farouk, R.; El-karadly, E.A.; Elwahy, A.H.M.; Mousa, A. Synthesis, characterization and application of reactive UV absorbers for enhancing UV protective properties of cotton fabric. Egyptian Journal of Chemistry 2020, 63, 525-536, http://doi.org/10.21608/ejchem.2020.22140.2324.

27. Xu, C.; Cao, L.; Su, G.; Liu, W.; Liu, H.; Yu, Y.; Qu, X. Preparation of ZnO/Cu2O compound photocatalyst and application in treating organic dyes. J. Hazard. Mater. 2010, 176, 807-813, https://doi.org/10.1016/j.jhazmat.2009.11.106.

28. Karthik, S.; Siva, P.; Balu, K.S.; Suriyaprabha, R.; Rajendran, V.; Maaza, M. Acalypha indica-mediated green synthesis of $\mathrm{ZnO}$ nanostructures under differential thermal treatment: Effect on textile coating, hydrophobicity, UV resistance, and antibacterial activity. Adv. Powder Technol. 2017, 28, 3184-3194, https://doi.org/10.1016/j.apt.2017.09.033.

29. Agnihotri, S.; Bajaj, G.; Mukherji, S.; Mukherji, S. Arginine-assisted immobilization of silver nanoparticles on $\mathrm{ZnO}$ nanorods: an enhanced and reusable antibacterial substrate without human cell cytotoxicity. Nanoscale 2015, 7, 7415-7429, http://doi.org/10.1039/C4NR06913G.

30. Pottathara, Y.B.; Thomas, S.; Kalarikkal, N.; Grohens, Y.; Kokol, V. Nanomaterials synthesis: Design, fabrication and applications. $1^{\text {st }}$ Edition ed.; Elsevier: 2019.

31. Basavegowda, N.; Idhayadhulla, A.; Lee, Y.R. Preparation of Au and Ag nanoparticles using Artemisia annua and their in vitro antibacterial and tyrosinase inhibitory activities. Materials Science and Engineering: C 2014, 43, 58-64, http://doi.org/10.1016/j.msec.2014.06.043.

32. Jose Varghese, R.; Zikalala, N.; Sakho, E.H.M.; Oluwafemi, O.S. 5 - Green synthesis protocol on metal oxide nanoparticles using plant extracts. In Colloidal Metal Oxide Nanoparticles, Thomas, S., Tresa Sunny, A., Velayudhan, P., Eds. Elsevier: 2020, http://doi.org/10.1016/b978-0-12-813357-6.00006-1.

33. Chen, H.-Y.; Yen, G.-C. Antioxidant activity and free radical-scavenging capacity of extracts from guava (Psidium guajava L.) leaves. Food Chem. 2007, 101, 686-694, https://doi.org/10.1016/j.foodchem.2006.02.047.

34. Somsri, S.; Sonwaew, W.; Rujiwatra, A. Psidium guajava Linn. extract mediated microwave synthesis and photocatalytic activities of $\mathrm{ZnO}$ nanoparticles. Mater. Lett. 2016, 177, 124-127, http://doi.org/10.1016/j.matlet.2016.04.130.

35. Lu, Z.; Gao, J.; He, Q.; Wu, J.; Liang, D.; Yang, H.; Chen, R. Enhanced antibacterial and wound healing activities of microporous chitosan-Ag/ZnO composite dressing. Carbohydr. Polym. 2017, 156, 460-469, http://doi.org/10.1016/j.carbpol.2016.09.051.

36. Pratiwi, M.K.; Masyrifah, L.; Hawa, L.C.; Dewi, S.R.; Izza, N.; Argo, B.D.; Sucipto, S.; Wibisono, Y. Enhanced antibiofouling properties of chitosan-based membranes by coating and blending of Moringa Oleifera L extracts. IOP Conference Series: Materials Science and Engineering 2018, 434, 012191, http://doi.org/10.1088/1757899x/434/1/012191.

37. Rehan, M.; Ahmed-Farid, O.A.; Ibrahim, S.R.; Hassan, A.A.; Abdelrazek, A.M.; Khafaga, N.I.M.; Khattab, T.A. Green and Sustainable Encapsulation of Guava Leaf Extracts (Psidium guajava L.) into Alginate/Starch Microcapsules for Multifunctional Finish over Cotton Gauze. ACS Sustainable Chemistry \& Engineering 2019, 7, 18612-18623, http://doi.org/10.1021/acssuschemeng.9b04952.

38. Rajendra, R.; Balakumar, C.; Ahammed, H.A.M.; Jayakumar, S.; Vaideki, K.; Rajesh, E. Use of zinc oxide nano particles for production of antimicrobial textiles. International Journal of Engineering, Science and Technology 2010, 2, 202-208.

39. ASTM E11-17, Standard Specification for Woven Wire Test Sieve Cloth and Test Sieves, ASTM International, West Conshohocken, PA, 2017. Available online: www.astm.org.

40. ISO 3310-1:2016. Test sieves. Technical requirements and testing. Test sieves of metal wire cloth. 2017.

41. ISO 565:1990. Test sieves — metal wire cloth, perforated metal plate and electroformed sheet — nominal sizes of openings. 2017.

42. ASTM Standard Test Method (D7334 - 08 (Reapproved 2013)). Standard practice for surface wettability of coatings, substrates and pigments by advancing contact angle measurement. ASTM International: West Conshohocken, PA, 2016.

43. Abo-Shosha, M.H.; Nassar, F.A.; El-Sayed, Z.; Hassabo, A.G. Preparation and characterizations of fatty acid/polyethylene glycol condensates and utilization as textile softeners. Research Journal of Textile and Apparel 2009, https://doi.org/10.1108/RJTA-13-02-2009-B006. 
44. Ibrahim, N.A.; Nada, A.A.; Eid, B.M.; Al-Moghazy, M.; Hassabo, A.G.; Abou-Zeid, N.Y. Nano-structured metal oxides: synthesis, characterization and application for multifunctional cotton fabric. Advances in Natural Sciences: Nanoscience and Nanotechnology 2018, 9, 035014, https://doi.org/10.1088/2043-6254/aadc2c.

45. As-Nzs. Australian/New Zealand Standard. Sun Protective Clothing-Evaluation and Classification. 1996.

46. Ibrahim, N.A.; Refai, R.; Youssef, M.A.; Ahmed, A.F. Proper finishing treatments for sun-protective cottoncontaining fabrics. J. Appl. Polym. Sci. 2005, 97, 1024-1032, http://doi.org/10.1002/app.21840.

47. Kamal, M.S.; Mahmoud, E.; Hassabo, A.; Eid, M.M. Effect of Some Construction Factors of Bi-layer Knitted Fabrics Produced for Sports Wear on Resisting Ultraviolet Radiation. Egyptian Journal of Chemistry 2020, 63, 5-6, http://doi.org/10.21608/ejchem.2020.25922.2514.

48. Kubelka, P. Ein Beitrag zur Optik der Farbanstriche (Contribution to the optic of paint). Zeitschrift fur technische Physik 1931, 12, 593-601.

49. Mehta, K.T.; Bhavsar, M.C.; Vora, P.M.; Shah, H.S. Estimation of the Kubelka-Munk scattering coefficient from single particle scattering parameters. Dyes and Pigments 1984, 5, 329-340, https://doi.org/10.1016/01437208(84)80027-3.

50. Waly, A.; Marie, M.M.; Abou-Zeid, N.Y.; El-Sheikh, M.A.; Mohamed, A.L. Process of Single-Bath Dyeing, Finishing and Flam-Retarding of Cellulosic Textiles in Presence of Reactive Tertiary Amines. 2006.

51. Waly, A.; Marie, M.M.; Abou-Zeid, N.Y.; El-Sheikh, M.A.; Mohamed, A.L. Flame retarding, easy care finishing and dyeing of cellulosic textiles in one bath. Egyptian Journal of Textile Polymer Science and Technology 2008, 12, 101-131.

52. Waly, A.; Marie, M.M.; Abou-Zeid, N.Y.; El-Sheikh, M.A.; Mohamed, A.L. Processes of Dyeing, Finishing and Flame Retardancy of Cellulosic Textiles in the Presence of Reactive Tertiary Amines. Research Journal of Textile and Apparel 2012, 16, 66-84, https://doi.org/10.1108/RJTA-16-03-2012-B007.

53. Hassabo, A.G. Preparation, characterisation and utilization of some textile auxiliaries. Cairo, Egypt: El-Azhar University 2005.

54. Abo-Shosha, M.; Nassar, F.; Hagag, K.; Mohamed, Z.; Hassabo, A. Utilization of Some Fatty Acid/PEG Condensates as Emulsifiers in Kerosene Paste Pigment Printing. Research Journal of Textile and Apparel 2009, $13,65-77$.

55. Hassabo, A.G.A.A. Synthesis and deposition of functional nano-materials on natural fibres. 2011.

56. Hassabo, A.G.; Mendrek, A.; Popescu, C.; Keul, H.; Möller, M. Deposition of Functionalized PolyethylenimineDye onto Cotton and Wool Fibres. Research Journal of Textile and Apparel 2014, 18, 36-49, https://doi.org/10.1108/RJTA-18-01-2014-B006.

57. Cai, Y.; Pailthorpe, M.T.; David, S.K. A New Method for Improving the Dyeability of Cotton with Reactive Dyes. Textile Research Journal 1999, 69, 440-446, http://doi.org/10.1177/004051759906900608.

58. ASTM Standard Test Method (D5035-2011 (Reapproved 2019)), Standard Test Method for Breaking Force and Elongation of Textile Fabrics (Strip Method), in ASTM International, 2019.

59. AATCC Test Method (66-2014). Wrinkle recovery of fabric: Recovery angle method. In Technical Manual Method American Association of Textile Chemists and Colorists: 2017; pp 113-116.

60. ASTM Standard Test Method (D7127 - 13). Standard test method for measurement of surface roughness of abrasive blast cleaned metal surfaces using a portable stylus instrument. ASTM International: West Conshohocken, PA, 2016.

61. ASTM Standard Test Method (D1388 - 14e1). Standard test methods for stiffness of fabrics. ASTM International: West Conshohocken, PA, 2018.

62. AATCC Test Method (100-2019). Assessment of antimicrobial finishes on textile materials. In Technical Manual Method American Association of Textile Chemists and Colorists: 2019. https://members.aatcc.org/store/tm100/513/.

63. El-Zawahry, M.M.; Hassabo, A.G.; Abdelghaffar, F.; Abdelghaffar, R.A.; Hakeim, O.A. Preparation and use of aqueous solutions magnetic chitosan / nanocellulose aerogels for the sorption of reactive black 5. Biointerface Research in Applied Chemistry 2021, 11, 12380-12402, https://doi.org/10.33263/BRIAC114.1238012402.

64. AATCC Test Method (147-2016). Antibacterial activity assessment of textile materials: Parallel streak. In Technical Manual Method American Association of Textile Chemists and Colorists: 2017; 275-276.

65. Hassabo, A.G.; Sharaawy, S.; Mohamed, A.L. Unsaturated fatty acids based materials as auxiliaries for printing and finishing of cellulosic fabrics. Biointerface Research in Applied Chemistry 2019, 9, 4284-4291, https://doi.org/10.33263/BRIAC95.284291.

66. Hebeish, A.; Shaarawy, S.; Hassabo, A.; El-Shafei, A. Eco-friendly multifinishing of cotton through inclusion of motmorillonite/chitosan hybrid Nanocomposite. Der Pharma Chemica 2016, 8, 259-271. 
67. Salama, M.; Hassabo, A.G.; El-Sayed, A.A.; Salem, T.; Popescu, C. Reinforcement of Polypropylene Composites Based on Recycled Wool or Cotton Powders. Journal of Natural Fibers 2017, 14, 823-836, https://doi.org/10.1080/15440478.2017.1279582.

68. Minella, M.; Minero, C. Quantification of the Photocatalytic Self-Cleaning Ability of Non-Transparent Materials. Materials 2019, 12, http://doi.org/10.3390/ma12030508.

69. Biswas, B.; Rogers, K.; McLaughlin, F.; Daniels, D.; Yadav, A. Antimicrobial Activities of Leaf Extracts of Guava (Psidium guajava L.) on Two Gram-Negative and Gram-Positive Bacteria. Int. J. Microbiol. 2013, 2013, 746165, http://doi.org/10.1155/2013/746165.

70. Metwally, A.M.; Omar, A.A.; Harraz, F.M.; El Sohafy, S.M. Phytochemical investigation and antimicrobial activity of Psidium guajava L. leaves. Pharmacogn. Mag. 2010, 6, 212, http://doi.org/10.4103/09731296.66939.

71. Dhiman, A.; Nanda, A.; Ahmad, S.; Narasimhan, B. In vitro antimicrobial activity of methanolic leaf extract of Psidium guajava L. Journal of Pharmacy and Bioallied Sciences 2011, 3, 226, http://doi.org/10.4103/09757406.80776.

72. Hassabo, A.G.; Mohamed, A.L.; Shaarawy, S.; Hebeish, A. Novel micro-composites based on phosphorylated biopolymer/polyethyleneimine/clay mixture for cotton multi-functionalities performance. Bioscience Research 2018, 15, 2568. 